\title{
Development zone spillover effect: the externality of the gathering of manufacturing enterprises
}

\author{
Yilin Wang ${ }^{1, *}$ \\ ${ }^{1}$ Public Finance, Zhongnan University of Economics and Law, China
}

\begin{abstract}
Using the data of manufacturing enterprises from 2003 to 2013 and the data of the state-level economic and technological development zone and high-tech development zone from 2010 to 2012, this paper uses BD-DD dual robust identification strategy to analyse the impact mechanism of the overflow effect of the establishment of state-level development zones by accurately judging the geographical relationship between enterprises and development zones. The results show that the development zone has a significant spillover effect on the surrounding manufacturing enterprises, and the total factor productivity of enterprises within $1000 \mathrm{~m}$ is about $9 \%$ higher than that of enterprises within $1000 \mathrm{~m}$ from the boundary of the development zone and the existence of Marshall's adjust theory is tested. Spillover effects have a range of $1000 \mathrm{~m}$ on innovation, while human capital is only $500 \mathrm{~m}$, indicating that knowledge spillover effects established in development zones are the main source of gathering externality. From the different characteristics of manufacturing, high-tech or mature manufacturing enterprises are more affected by spillover effects, possibly because high-tech or mature enterprises and regional enterprises overlap more in factors of production or technology, it is more likely to form Marshall cluster externality.
\end{abstract}

\section{Introduction}

The development zone is an important industrial policy for Chinese government to guide the industry to gather, develop the open economy and promote the local economic development. Many studies have also found that development zone has a catalysing effect on the output, investment and efficiency of enterprises(Wang,2013;Zhang et al,2016). ${ }^{[3]-[4]}$ If the production efficiency of enterprises outside the scope of the development zone has also improved after the policy, it means that in addition to the efficiency improvement brought about by the adjust of enterprises in the development zone, it also plays a positive role in promoting the local economy, which is also an important purpose of the development zone policy-making.

However, there is a lack of means to judge the relative geographical location of enterprises, and the research on the effect of development zone pays more attention to the influence brought about by the clustering effect. From the perspective of local government's economic development, the overall impact of the development zone on the local economy is more important. Zheng et al. (2017) has the similar ideas with the study: the impact of the spillover effects of the development zone on TFP and consumer activities such as retail and real estate in the surrounding regions was analyzed using micro-enterprise data. ${ }^{[5]}$ But Zheng et al. (2017) The single-center city hypothesis is that the same area from the city center is completely replaceable, which is difficult to coincide with the current situation of urban development in China, and cross-sectional regression is difficult to control the interference of factors that change over time. ${ }^{[5]}$

The reasons why the spillover effect in the development zone causes concern is the necessity and importance of the study from the perspective of explaining the mechanism causes of the spillover effect. Domestic scholars on the above spillover effects of the study is very few.

Therefore, this paper analyzes the characteristics and impact paths of the spillover effects of the establishment of development zones on local enterprises using manufacturing enterprise data for 2003-2013 and national development zone data for 2010-2012. This study will provide a new perspective for assessing the impact of development zone policies on the local economy and provide a reference for future economic policy formulation.

\section{Theoretical Framework and Hypothesis}

The starting point of this paper is that the development zone will produce the externality of enterprise ad collecting, and this externality can have spillover effects in labour market, intermediate products, knowledge spillover and so on. We first guide our empirical study by establishing a simple homogeneity enterprise model that shows how the spillover effects of the development zone affect the local decisions of the surrounding

\footnotetext{
* Corresponding author: yilinsdhh@163.com
} 
enterprises, and then incorporating the heterogeneity of the enterprise into the model to examine the differences in the impact of the spillover effects on different types of enterprises.

\subsection{Effecting Mechanism}

Based on Marshall's economic theory of a clustering, the spillover effect of the development zone is the manifestation of the externality of the enterprise a cluster, and the enterprises gathered around the development zone increase productivity by sharing the thick labour market, low-cost intermediate products, and obtaining knowledge spillover with the enterprises in the region.

Development zones create a thick labour market, and external enterprises close to the border are able to share the labour market with enterprises in the region, thereby improving the quality of their human capital.

The knowledge spillover generated by the innovation activities of enterprises in the development zone will also improve the innovation level of the surrounding enterprises. The development zone promotes innovation between enterprises in the region in terms of policy incentives and enterprise screening.

Finally, companies around the development zone can also share the intermediates market with companies in the region to increase productivity by providing quality services and middlemen (Glaeser and Kohlhase,2003) at a lower cost. ${ }^{[1]}$

\subsection{Homogeneity enterprises}

Consider a fully competitive market, and the enterprises around the development zone use labour, capital, and land for production at a given price (standardized to 1). The enterprise chooses labour Capital and land the amount of input to maximize profits:

$$
\operatorname{Max} f(A, L, K, T)-w L-r K-q T
$$

Above this, w, $\mathrm{r}$ and q represents the factor price, A represents total factor productivity (TFP)for an enterprise. The change of A represents the spillover effect. Under the condition that the endo-technology of the enterprise is unchanged, the spillover effect of enterprise can affect the enterprise TFP by affecting the human capital quality $(\mathrm{H})$ and innovation level(N) of the enterprises around the development zone. It is generally believed that the quality and level of innovation of human capital in an enterprise is positively related to TFP: $\quad \partial \mathrm{A} / \partial \mathrm{H}>0, \partial \mathrm{A} / \partial \mathrm{N}>0$. In order to explore the mechanism of spillover effect affecting enterprise TFP, the quality of capital and the level of enterprise innovation are the distance(d) from the boundary of the development zone Functions of : $\mathrm{H}=\mathrm{H}(\mathrm{d}), \mathrm{N}=\mathrm{N}(\mathrm{d})$. At the same time, because the development zone is full of high-tech enterprises, and has a sound infrastructure, so we believe that the closer to the boundary of the development zone, the higher the quality of human capital and the level of enterprise innovation: $\partial \mathrm{H} / \partial \mathrm{d}<0, \partial \mathrm{N} / \partial \mathrm{d}<0$.
The optimal factor input and labor supply function and land supply function are substituted to solve the expression of enterprise profit maximization:

$$
\begin{aligned}
& \pi^{*}=f\left(A(H(d), N(d)), L^{*}(w(d), r, q(d)), K^{*}\right. \\
& \left.(w(d), r, q(d)), T^{*}(w(d), r, q(d))\right)-w L^{*}(w(d), r, q(d))-r K^{*} \\
& (w(d), r, q(d))-q T^{*}(w(d), r, q(d))
\end{aligned}
$$

It can be seen that the enterprise TFP,wages and land prices are the distance from the boundary of the development zone the function of . Pair the upper sides to the distance(d), then we find a guide:

$$
\begin{aligned}
& \partial \pi^{*} / \partial N=(\partial f / \partial A) *(\partial A / \partial N)- \\
& {\left[(\partial w / \partial N) L^{*}+(\partial q / \partial N) T^{*}\right]+\left[\left(\partial L^{*} / \partial w\right) *\left(\partial w / \partial N^{*}\right)+\left(\partial L^{*} / \partial\right.\right.} \\
& \left.q) *(\partial q / \partial N)\left(\partial f / \partial L^{*}-w\right)\right]+\left[\left(\partial K^{*} / \partial w\right) *(\partial w / \partial N)+\left(\partial K^{*} / \partial q\right)\right. \\
& *(\partial q / \partial N)\left(\partial f / \partial K^{*}-\right. \\
& r)]+\left[\left(\partial T^{*} / \partial w\right) *(\partial w / \partial N)+\left(\partial T^{*} / \partial q\right) *(\partial q / \partial N)\left(\partial f / \partial T^{*}-q\right)\right]
\end{aligned}
$$

In a fully competitive market, the marginal output of the factor is equal to its price, so the upper can be simplified to:

$$
\begin{aligned}
& \partial \pi^{*} / \partial d=(\partial f / \partial A) *[(\partial A / \partial H) *(\partial H / \partial d)+(\partial A / \partial N) *(\partial N / \partial d)] \\
& \left.-(\partial w / \partial d) L^{*+}(\partial q / \partial d) T^{*}\right)
\end{aligned}
$$

\subsection{Heterogeneous Enterprises}

Since the market is completely competitive, in the long run the excess profit earned by the company due to its position advantage is zero, and we get:

$$
\begin{aligned}
& (\partial f / \partial A) *[(\partial A / \partial H) *(\partial H / \partial d)+(\partial A / \partial N) *(\partial N / \partial d)]=(\partial w / \partial d) \\
& \left.L^{*}+\partial q / \partial d T^{*}\right)
\end{aligned}
$$

We set $\varphi=[(\partial \mathrm{A} / \partial \mathrm{H})(\partial \mathrm{H} / \partial \mathrm{d})+(\partial \mathrm{A} / \partial \mathrm{N})(\partial \mathrm{N} / \partial \mathrm{d})]$, simplified to:

$$
(\partial f / \partial A) * \varphi=(\partial w / \partial d) L^{*+}(\partial q / \partial d) T^{*}
$$

Two types of enterprises are considered: high-tech enterprises and low-tech enterprises, and assuming that the two types of enterprises have the same distance to the boundary of the development zone, the price of the land they use should also be equal.

Suppose that both types of enterprises use production techniques, in the case of the same number of factor inputs for both types of enterprises: $\partial f_{H} / \partial A_{H}=\partial f_{L} / \partial A_{L}$, and we get:

$$
\left|\varphi_{H}\right|>\left|\varphi_{L}\right|
$$

This suggests that in the long run, the spillover effect of the development zone may have a greater impact on high-tech enterprises than that of low-tech enterprises. Similarly, assuming that the quality of human capital of mature enterprises is higher than that of young enterprises, mature enterprises may be more affected by spillover effects. The reason may be that the development zone is full of high-tech enterprises, hightech or mature enterprises in human capital, technology, intermediate input and other aspects of the overlap with 
enterprises in the region is higher, so it is easier to form cooperation and learning effects.

\subsection{Assumptions}

We get four study hypotheses:

Hypothesis 1: The cluster of enterprises around the development zone is due to the existence of spillover effects, which make the TFP of enterprises around the development zone higher than that of enterprises farther away.

Hypothesis 2: The spillover effect may improve the TFP of the enterprise by improving the quality of human capital of the surrounding enterprises, so the quality of human capital of the enterprises around the development zone will be higher than that of the enterprises farther away.

Hypothesis 3: The spillover effect may improve the TFP by improving the innovation ability of the surrounding enterprises, so the innovation level of the enterprises around the development zone will be higher than that of the distant enterprises.

Hypothesis 4: Because high-tech or mature enterprises in the region have higher overlap in factors of production or technology, the spillover effect on mature enterprises and high-tech enterprises is more obvious.

\section{Empirical Model}

The implementation effect of development zone policy may vary from region to region or type, and the resulting spillover effect size may vary, so we need to identify and control the implementation effect of development zone policy first. Within the framework of BD-DD analysis, we use the methods of $\mathrm{Lu}$ et $\mathrm{al}(2019)$ and Miguel and Kremer(2004)to identify the impact of development zone spillover effects on the productivity of surrounding businesses. $^{[2]}$ We assume that there is a range of spillover effects in the development zone, e.g. enterprises within $1000 \mathrm{~m}$ of the boundary of the development zone will be affected by the spillover effect, while enterprises other than $1000 \mathrm{~m}$ will not be affected by the spillover effect or will have a very weak impact." We can then estimate the size of the spillover effect by comparing the difference between enterprise TFP within $1000 \mathrm{~m}$ and $1000 \mathrm{~m}$ from the development zone boundary. Specifically, we build the following model:

Table 1. The results of the regression of the baseline model

\begin{tabular}{|l|c|c|c|c|c|}
\hline & $(1)$ & $(2)$ & $(3)$ & $(4)$ & $(5)$ \\
\hline Inner ring & $0-500 \mathrm{~m}$ & $0-500 \mathrm{~m}$ & $0-500 \mathrm{~m}$ & $0-1000 \mathrm{~m}$ & $0-1000 \mathrm{~m}$ \\
\hline Outer ring & $500-1000 \mathrm{~m}$ & $1000-1500 \mathrm{~m}$ & $1000-2000 \mathrm{~m}$ & $1000-1500 \mathrm{~m}$ & $1000-2000 \mathrm{~m}$ \\
\hline Explanatory Variable & $\mathrm{tfp} \_\mathrm{lp}$ & $\mathrm{tfp} \_\mathrm{lp}$ & $\mathrm{tfp} \_\mathrm{lp}$ & $\mathrm{tfp} \_\mathrm{p}$ & $\mathrm{tfp} \_\mathrm{lp}$ \\
\hline \hline D_vicinity*Post*D & -0.0218 & 0.0277 & $0.0947^{*}$ & 0.0569 & $0.101^{* *}$ \\
\hline & $(0.0806)$ & $(0.0539)$ & $(0.0495)$ & $(0.0478)$ & $(0.0458)$ \\
\hline D_vicinity*Post & 0.109 & $0.204^{* * *}$ & $0.0878^{* *}$ & $0.192^{* * *}$ & $0.0904 * *$ \\
\hline & $(0.0856)$ & $(0.0555)$ & $(0.0432)$ & $(0.0488)$ & $(0.0387)$ \\
\hline Control variables & $\mathrm{Y}$ & $\mathrm{Y}$ & $\mathrm{Y}$ & $\mathrm{Y}$ & $\mathrm{Y}$ \\
\hline Provincial fixed effect & $\mathrm{Y}$ & $\mathrm{Y}$ & $\mathrm{Y}$ & $\mathrm{Y}$ & $\mathrm{Y}$ \\
\hline Industry fixed effect & $\mathrm{Y}$ & $\mathrm{Y}$ & $\mathrm{Y}$ & $\mathrm{Y}$ & $\mathrm{Y}$ \\
\hline $\mathrm{N}$ & 8,252 & 12,380 & 17,646 & 15,300 & 20,566 \\
\hline
\end{tabular}


The inner ring in Table 1 refers to the area bandwidth of the adjacent development zone and the outer ring refers to the area bandwidth away from the development zone. We use two defining methods for inner and outer ring bandwidth: inner ring $0-500 \mathrm{~m}$ and $500-1000 \mathrm{~m}$, outer ring $1000-1500 \mathrm{~m}$ and $1000-2000 \mathrm{~m}$. As can be seen from-of columns(2)-(6), the interaction factors we are concerned about D_vicinity are significantly positive, indicating that the development area has spillover effects on the surrounding area and improves the TFP of the surrounding enterprises. This conclusion is still stable under the condition of adding control variables and fixed effects. In addition, it should be noted that in column (1) we hypothetically define the outer ring as $500-1000 \mathrm{~m}$ for regression as a placebo test. The regression results show that the D vicinity (the "post") coefficient is not significant, which is in line with our expectations. This indicates that the spillover effect of the development zone on the surrounding area is approximately $1000 \mathrm{~m}$ near its boundary. The baseline regression results provide evidence for Hypothesis I.

\subsection{Robustness Test of the Return of the Benchmark}

In order to ensure the reliability of the benchmark regression results, we again use the double differential method to test the spillover effect of the development zone. Specifically, we take the inner $\operatorname{ring}(0-1000 \mathrm{~m})$ enterprise as the experimental group, and the outer ring $(1000-2000 \mathrm{~m})$ enterprise as the control group to regression of (2). Table 2 reports regression results.

Table 2. The robustness test for baseline regression

\begin{tabular}{|l|c|c|c|c|}
\hline & $(1)$ & $(2)$ & $(3)$ & $(4)$ \\
\hline Inner ring & $0-500 \mathrm{~m}$ & $0-500 \mathrm{~m}$ & $0-1000 \mathrm{~m}$ & $0-1000 \mathrm{~m}$ \\
\hline Outer ring & $\begin{array}{c}1000- \\
1500 \mathrm{~m}\end{array}$ & $\begin{array}{c}1000- \\
2000 \mathrm{~m}\end{array}$ & $\begin{array}{c}1000- \\
1500 \mathrm{~m}\end{array}$ & $\begin{array}{c}1000- \\
2000 \mathrm{~m}\end{array}$ \\
\hline $\begin{array}{l}\text { Explanatory } \\
\text { variable }\end{array}$ & tfp_lp & tfp_lp & tfp_lp & tfp_lp \\
\hline \hline D_near & -0.0656 & -0.0362 & -0.0182 & 0.0303 \\
\hline Post & $(0.0536)$ & $(0.0487)$ & $(0.0309)$ & $(0.0262)$ \\
\hline $\begin{array}{c}0.293^{* *} \\
*\end{array}$ & $\begin{array}{c}0.295^{* *} \\
*\end{array}$ & $\begin{array}{c}0.266^{* *} \\
*\end{array}$ & $\begin{array}{c}0.289^{* *} \\
*\end{array}$ \\
\hline $\begin{array}{l}\mathrm{D} \text { _near*Pos } \\
\mathrm{t}\end{array}$ & $\begin{array}{c}0.200^{* *} \\
(0.0413)\end{array}$ & $\begin{array}{c}0.195^{* *} \\
(0.0398)\end{array}$ & $\begin{array}{c}0.123^{* *} \\
(0.0296)\end{array}$ \\
\hline $\begin{array}{l}\text { Control } \\
\text { variables }\end{array}$ & $\mathrm{Y}$ & $\mathrm{Y}$ & $\mathrm{Y}$ & $\mathrm{Y}$ \\
\hline $\begin{array}{l}\text { Provincial } \\
\text { fixed effect }\end{array}$ & $\mathrm{Y}$ & $\mathrm{Y}$ & $\mathrm{Y}$ & $\mathrm{Y}$ \\
\hline $\begin{array}{l}\text { Industry } \\
\text { fixed effect }\end{array}$ & $\mathrm{Y}$ & $\mathrm{Y}$ & $\mathrm{Y}$ & $\mathrm{Y}$ \\
\hline $\mathrm{N}$ & 4,810 & 7,978 & 7,730 & 10,898 \\
\hline
\end{tabular}

As can be seen from the regression(1)-(3) results of the interactions(D_near*Post), the interactions we are concerned with are significantly positive at 5\% level, but the interaction coefficients in column(4) are significantly positive at $10 \%$ level, possibly because the spillover effect has weakened considerably at close to $1000 \mathrm{~m}$.
Overall, the robustness test results still support the main conclusions of our benchmark regression.

\section{Main Conclusions and Implications}

First, hypothesis 1 is verified by benchmark regression. We find that the development zone has spillover effect on the surrounding area of about $1000 \mathrm{~m}$, which is manifested in improving the TFP, of the surrounding enterprises, which is consistent with the conclusion of the Zheng et al (2019). ${ }^{[8]}$ Secondly, the double difference method is used to verify hypothesis two and hypothesis three, which shows that the positive influence of spillover effect on the TFP of surrounding enterprises is mainly caused by the externality of agglomeration effect. Finally, this paper also examines the heterogeneity of spillover effects on enterprises with different technical levels and ages. It is found that high-tech and mature enterprises benefit more from spillover effect, which may be due to the higher overlap of production factors or technologies between high-tech enterprises or mature enterprises and regional enterprises. Therefore, it is easier to form cooperation and learning effect.

Based on the above conclusions, we have the following enlightenment: The development zone not only needs to cultivate high-tech industries to promote the upgrading of industrial structure, but also undertakes the task of driving regional economic development, and the micro basis of economic development is the growth of enterprises $(\mathrm{Li}, \mathrm{Wu}, 2018)^{[6]}$. Based on the research, it is found that the development zone has spillover effect on the enterprises in the range of about $1000 \mathrm{~m}$, and the high-tech or mature enterprises are more affected by the spillover effect. This shows that the local government should consider the influence of the policy on the overall industrial agglomeration structure when implementing the development zone policy. If the new industrial agglomeration structure cannot be formed around the development zone, then the establishment of the development zone will inevitably reduce the original industrial agglomeration level. This will not be conducive to the long-term development of the industry.

\section{References}

1. Black, S. E., 1999, "Do Better Schools Matter? Parental Valuation of Elementary Education", The Quarterly Journal of Economics, 114(2), 577-99.

2. Miguel, E., and M. Kremer, 2004, "Worms: Identifying impacts on education and health in the presence of treatment externalities " , Econometrica, 72(1), 159-217.

3. Wang, J., 2013, "The economic impact of Special Economic Zones: Evidence from Chinese municipalities", Journal of Development Economics, 101(1), 133-47.

4. Zhang, Wang and Zheng, 2016, Development Zone and Dynamic Growth Mechanism of Enterprises: A 
Study Based on the Entry, Exit and Growth of Enterprisesn, Financial Research,12.

5. Zheng, S., W. Sun, J. Wu, and M. E. Kahn, 2017, "The birth of edge cities in China: Measuring the effects of industrial parks policy", Journal of Urban Economics, 100, 80-103.

6. Li and $\mathrm{Wu}, 2018$, Development zone establishment and firm growth: heterogeneity and mechanism, Chinese industrial economy, 4 . 